\section{Terrestrial Ostracods of New Zealand}

Terrestrial ostracods have been known since 1953 from South Africa when Dr. R. F. Lawrence found specimens of Mesocypris terrestris Harding, in the humus of the Knysna forest ${ }^{I}$. Although there is no published record they have been found on several occasions in New Zealand, also in forest litter. Specimens from Leith Saddle, Dunedin, have recently been extracted alive by slowly drying out litter in a Berlese funnel, with a water-jacket maintained at a temperature of $40^{\circ} \mathrm{C}$. and with the end leading into water, not alcohol. The temperature must be low to prevent the ostracods closing their valves and remaining immobile, and this is probably the reason why they have been found so infrequently. The animals are easily kept alive in a small dish lined with moist filter paper, and with a few fragments of humus to provide food and shelter.

The New Zealand specimens also appear to belong to the genus Mesocypris Daday, but differ in several respects from other described species. The valves of the shell are of equal size. Typical dimensions are : length, $0.56 \mathrm{~mm}$., and height, $0.28 \mathrm{~mm}$., the colouring being pale lemon unevenly distributed. Two specimens of the fifty which I have seen are considerably larger, being as much as $1.04 \mathrm{~mm}$. long and $0.62 \mathrm{~mm}$. high. The colour is also different, with patches of light brown. No males have yet been found. There is a marked dorso-ventral flattening, and the shell is moderately hairy. The appendages are broadly similar to those of $M$. terrestris with well-developed claws and a reduced number of setæ. A full description will be published later.

Locomotion is by means of the second antennæ and the third legs, both of which are armed with elaws at the tips. An extra leg, used also for balance in steep places, is provided by the two halves of the furca, which act together. The animals are capable of moving up and down vertical slopes of humus, and one specimen was seen to climb several centimetres up the smooth sides of a glass dish. The first antennæ are used for sensory perception and balance, and with the setæ spread out explore objects ahead of the animal. They maintain a constant up and down motion, each alternating with the other. Sudden intense illumination causes the valves to close while bright light leads to rapid wandering in search of shelter. It is surprising to find apparently normal eyes, as Harding states that $M$. terrestris, like most litter-dwelling animals, appeared to be blind.

The Dunedin specimens were collected in ordinary forest litter from podocarp-broadleaf forest on Leith Saddle at an altitude of $1,200 \mathrm{ft}$. in places of no more than ordinary dampness. Experiments in the laboratory have shown that they are able to survive quite marked drying-out although their activity decreases considerably and they tend to remain in holes in the humus. On the addition of more water they emerge and are capable of moving with great speed. On the other hand total immersion does not harm them and they will survive for at least a week. It is interesting that terrestrial Harpacticoid copepods were also found in the same habitat.

Other specimens known to me have been collected from Mount Arthur at 3,200 ft. (J. T. Salmon; 1946), Stewart Island (R. K. Dell and B. A. Holloway; 1955), Mount Egmont in sub-alpine forest (M. P. Büchler ; 1954), at the foot of Mount Burnett, Nelson (R. Chapman; 1956), beech litter from
Silverstream (J. D. Stout), Little Barrier Island $800 \mathrm{ft}$. (A. Chapman; 1959).

Further studies are in progress on the ecology and distribution of this New Zealand terrestrial ostracod.

Department of Zoology,

University of Otago,

$$
\text { Dunedin. }
$$

${ }^{1}$ Harding, J. P., Ann. Natal Mus., 12, 359 (1953).

\section{Ovaries of Glossina morsitans}

CORRELATED with the viviparous type of reproduction found in the tsetse files, the essential features of which were worked out as early as 1895 by Bruce ${ }^{1}$, there is a great reduction in the number of ovarioles. Stuhlman ${ }^{2}$ and Roubaud ${ }^{3}$ studied the anatomy of the female reproductive organs and considered that each ovary consisted of a single ovariole, a view which has been perpetuated by every subsequent author. This communication, however, reports that in Glossina morsitans dissections have proved that each ovary contains, in fact, two ovarioles.

Dissections of teneral females were carried out in 0.9 per cent saline on a microscope slide. The ovarian sheaths were stripped off with a fine needle and the two ovarioles in each ovary released (Fig. 1, $a, b)$. The slide was then drained of the excess saline and the ovaries mounted directly in a drop of polyvinyl-lactophenol containing a little lignin pink. This mountant produced a permanent preparation and avoided distortion of the ovarioles.

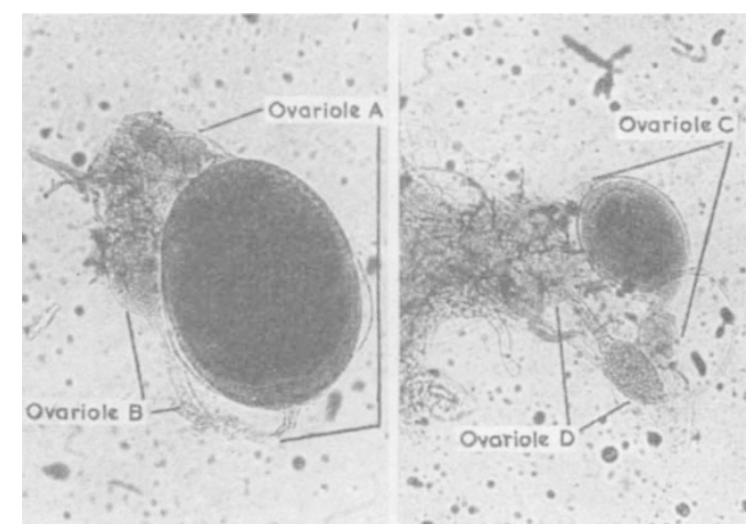

(a)

(b)

Fig. 1. (a) Right ovary of a 24-hur.-old Glossina morsitans, dissected to show the two ovarioles. (b) Left ovary, ditto

In a study of the ovulation cycle of female $G$. palpalis, Helen Mellanby ${ }^{4}$ showed that the first egg is ovulated from the right ovary, and the subsequent eggs alternately from left and right ovaries throughout the reproductive life of the fly. The cycles in $G$. morsitans and $G$. swynnertoni have been shown to be the same ${ }^{5}$. In the light of the fact that there is a total of four ovarioles, however, the ovulation crele in Glossina requires a more detailed study. Fig. 2 shows the four ovarioles completely removed from the ovaries of a $24-\mathrm{hr}$. old female $G$. morsitans. The most advanced egg follicle is in one $(A)$ of the two ovarioles in the right ovary; the ovum and yolk occupy about the lower third of the follicle. The 